\title{
Transient Receptor Potential Ankyrin 1 Is Check for updates Up-Regulated in Response to Lipopolysaccharide via P38/Mitogen-Activated Protein Kinase in Dental Pulp Cells and Promotes Mineralization
}

Kento Tazawa, Nobuyuki Kawashima, Masashi Kuramoto, Sonoko Noda, Mayuko Fujii, Keisuke Nara, Kentaro Hashimoto, and Takashi Okiji

\author{
Accepted for publication \\ August 24, 2020. \\ Address correspondence to \\ Kento Tazawa, Ph.D., or \\ Nobuyuki Kawashima, Ph.D., \\ Graduate School of Medical and \\ Dental Sciences, Tokyo Medical \\ and Dental University, 1-5-45 \\ Yushima, Bunkyo-ku, Tokyo \\ 113-8549, Japan. E-mail: \\ kenendo@tmd.ac.jp or \\ kawashima.n.endo@tmd.ac.jp.
}

\begin{abstract}
Increased expression of the transient receptor potential ankyrin 1 (TRPA1) channel has been detected in carious tooth pulp, suggesting involvement of TRPA1 in defense or repair of this tissue after exogenous noxious stimuli. This study aimed to elucidate the induction mechanism in response to lipopolysaccharide (LPS) stimulation and the function of TRPA1 in dental pulp cells. Stimulation of human dental pulp cells with LPS up-regulated TRPA1 expression, as demonstrated by quantitative RT-PCR and Western blotting. LPS stimulation also promoted nitric oxide (NO) synthesis and p38/mitogen-activated protein kinase (MAPK) phosphorylation. NOR5, an NO donor, up-regulated TRPA1 expression, whereas 1400W, an inhibitor of inducible nitric oxide synthase, and SB202190, a p38/MAPK inhibitor, downregulated LPS-induced TRPA1 expression. Moreover, JT010, a TRPA1 agonist, increased the intracellular calcium concentration and extracellular signal-regulated kinase 1/2 phosphorylation, and up-regulated alkaline phosphatase mRNA in human dental pulp cells. Icilin-a TRPA1 agonist-up-regulated secreted phosphoprotein 1 mRNA expression and promoted mineralized nodule formation in mouse dental papilla cells. In vivo expression of TRPA1 was detected in odontoblasts along the tertiary dentin of carious teeth. In conclusion, this study demonstrated that LPS stimulation induced TRPA1 via the N0-p38 MAPK signaling pathway and TRPA1 agonists promoted differentiation or mineralization of dental pulp cells. (Am J Pathol 2020, 190: 2417-2426; https://doi.org/10.1016/j.ajpath.2020.08.016)
\end{abstract}

Dental pulp is a soft connective tissue consisting of odontoblasts, dental pulp fibroblasts, immunocompetent cells, and vascular and nervous systems, which is characterized by the anatomic feature of being surrounded by hard tissue named dentin that acts as a physical barrier against various exogenous stimuli. ${ }^{1}$ However, invasion by bacteria or bacterial products entering via dentinal tubules from carious lesions induces pulpal inflammation as a defense reaction against exogenous invasion. ${ }^{2}$ Hypersensitivity and allodynia to cold and heat stimuli are typical clinical symptoms of pulpal inflammation, ${ }^{3}$ and are considered to be induced by reduction of the transduction threshold of temperature-sensitive receptors via the action of several inflammatory mediators, such as ATP, bradykinin, prostaglandins, and histamine. ${ }^{4}$
The transient receptor potential (TRP) family members are temperature-sensitive cation channels that play a major role in sensing hot and cold temperatures, as well as pain perception associated with temperature. TRP ankyrin 1 (TRPA1), a member of the TRP family, was initially identified as a cold-sensitive ion channel in a subset of nociceptive sensory dorsal root ganglion neurons. ${ }^{5}$ Recently, TRPA1 has been recognized as a polymodal nociceptor activated by mechanical stimulation and various chemical

Supported by Japan Society for the Promotion of Science (JSPS) Grantsin-Aid for Scientific Research (KAKENHI) 18K17039 (K.T.), $20 \mathrm{~K} 18499$ (S.N.), 20K18496 (M.F.), 20K18526 (K.N.), and 19K24137 (K.H.).

Disclosures: None declared. 
irritants, such as acyl isothiocyanate, acrolein, and formalin, as well as noxious cold stimulation $\left(<17^{\circ} \mathrm{C}\right){ }^{6}$ TRPA1 is expressed in nerve fibers, ${ }^{5}$ but recent studies have revealed that TRPA1 is also expressed in nonneural cells and plays a role in various physiological functions. ${ }^{6}$ These functions include the release of IL-8 in human airway/lung epithelial cells, ${ }^{7}$ promotion of vasodilation in vascular endothelial cells, ${ }^{8}$ acceleration of insulin secretion in pancreatic $\beta$ cells, ${ }^{9}$ and induction of erythema in keratinocytes and fibroblasts of human skin. ${ }^{10}$ Expression of TRPA1 has also been reported in dental pulp cells. ${ }^{11}$ However, its physiological function in this tissue is not fully understood.

Inflammation modulates the expression and function of TRPA1 channels, which are considered to be associated with various inflammatory events, such as hyperalgesia, allodynia, and extravasation. ${ }^{12-14}$ TRPA1 expression increases in tyrosine receptor kinase A-expressing rat dorsal root ganglion neurons following peripheral inflammation. ${ }^{12}$ In human fibroblast-like synoviocytes, major inflammatory mediators, such as tumor necrosis factor- $\alpha$ and IL- $1 \alpha$, induce expression of TRPA1 via NF- $\kappa \mathrm{B}$ signaling and downstream activation of the transcription factor hypoxiainducible factor $1 \alpha$ (HIF $1 \alpha){ }^{15}$ In dental pulp, enhanced expression of TRPA1 is observed in odontoblasts of carious teeth, whereas low or little expression of TRPA1 is detected in the pulp tissue of intact teeth. ${ }^{16}$ Tumor necrosis factor- $\alpha$ induces TRPA1 via $\mathrm{p} 38 / \mathrm{mitogen}$-activated protein kinases (MAPKs) in odontoblast-like cells in vitro ${ }^{17}$; however, precise mechanisms that induce TRPA1 expression in dental pulp cells or odontoblasts in response to infection or inflammation remain unclear. Furthermore, the function of TRPA1 in inflamed pulp tissue has not fully been elucidated.

Therefore, this study aimed to explore intracellular signaling pathways involved in the induction of TRPA1, and elucidate the function of TRPA1 in dental pulp cells.

\section{Materials and Methods}

\section{Immunohistochemistry}

The experimental protocol was approved by the Ethics Committee of the Faculty of Dentistry, Tokyo Medical and Dental University (D2014-039). Informed consent was obtained from each patient. Permanent vital teeth with deep caries $(n=3)$ or without caries $(n=3)$ extracted from healthy patients (age, 19 to 36 years) for orthodontic reasons were used in this study. The extracted teeth were horizontally divided into coronal and root portions. The coronal portions were fixed with $4 \%$ paraformaldehyde at $4^{\circ} \mathrm{C}$ overnight, demineralized with $17 \%$ EDTA at $4^{\circ} \mathrm{C}$ for 8 weeks, and processed for vertically cut cryostat sections (10 $\mu \mathrm{m}$ thick).

The sections were incubated with a rabbit polyclonal anti-TRPA1 antibody (1:500; ACC-037; Alomone Labs, Jerusalem, Israel) or Alexa Fluor 488-conjugated mouse monoclonal anti-nestin antibody (1:100; 53-9843-80; eBioscience, San Diego, CA) at $4{ }^{\circ} \mathrm{C}$ overnight, followed by incubation with Alexa Fluor 568-conjugated donkey antirabbit IgG (1:500; ab175692; Abcam, Cambridge, UK) at room temperature for 60 minutes. DAPI was used for counterstaining. Normal rabbit and mouse sera were applied instead of primary antibodies for negative controls.

\section{Cell Culture, Inhibitors, N0 Donor, and TRPA1 Agonists}

Human dental pulp cells (hDPCs) were isolated from dental pulp tissues of wisdom teeth $(n=7 ; 20$ to 33 years old; approved by the Ethics Committee of Tokyo Medical and Dental University, D2014-039), as reported previously. ${ }^{18}$ In brief, the extracted teeth were divided longitudinally, and the whole pulp tissue was extracted. The pulp tissue was minced and digested with Liberase (Roche, Basel, Switzerland) for 40 minutes at $37^{\circ} \mathrm{C}$, and a single cell suspension obtained with a cell strainer $(70 \mu \mathrm{m}$ diameter; BD Falcon, Franklin Lakes, NJ) was used as hDPCs. hDPCs were cultured in $\alpha$-minimum essential medium (Wako, Osaka, Japan) supplemented with $10 \%$ fetal bovine serum (HyClone, South Logan, UT) and 1\% penicillin/streptomycin (Wako). Cells were maintained at $37^{\circ} \mathrm{C}$ with $5 \% \mathrm{CO}_{2}$ and $100 \%$ relative humidity. Cells at passages 4 to 7 were used in the following experiments.

hDPCs were cultured in 6-well plates $\left(1.5 \times 10^{5}\right.$ cells/ well) with or without lipopolysaccharide (LPS) for 24 or 48 hours (100 ng/mL; Escherichia coli O111B4; Merck, Kenilworth, NJ). RAW264.7 mouse macrophage cell line was cultured in Dulbecco's modified Eagle's medium supplemented with $10 \%$ heat-inactivated fetal bovine serum (HyClone) and $1 \%$ penicillin/streptomycin at $37^{\circ} \mathrm{C}$ with $5 \%$ $\mathrm{CO}_{2}$ and $100 \%$ relative humidity. The following chemicals were used in this study: BAY 11-7085 (NF- $\kappa$ B inhibitor; 1 $\mu \mathrm{mol} / \mathrm{L}$; 196309-76-9; Cayman Chemical, Ann Arbor, MI),

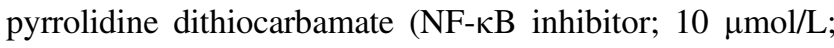
ab141406; Abcam), SB202190 (p38/MAPK inhibitor; 1 $\mu \mathrm{mol} / \mathrm{L}$; S-1700; LC Laboratories, Woburn, MA), 1400W [inducible nitric oxide synthase (iNOS) inhibitor; $1 \mu \mathrm{mol} / \mathrm{L}$; 100050; Merck], NOR5 (NO donor; $100 \mu \mathrm{mol} / \mathrm{L} ; 348$ 08011; Dojindo Molecular Technologies, Kumamoto, Japan), JT010 (TRPA1 agonist; $200 \mathrm{nmol} / \mathrm{L}$ or $2 \mu \mathrm{mol} / \mathrm{L}$; SML 1672; Sigma Aldrich, St. Louis, MO), icilin [TRPA1/ transient receptor potential melastatin 8 (TRPM8) agonist; 2 $\mu \mathrm{mol} / \mathrm{L}$; 1531; Tocris Bioscience, Bristol, UK], HC-030031 (TRPA1 inhibitor; $10 \mu \mathrm{mol} / \mathrm{L}$; 086-09961; Wako), and A967079 (TRPA1 inhibitor; $2 \mu \mathrm{mol} / \mathrm{L}$; 010-26981; Wako). NOR5 was applied for 6 hours to evaluate the effect on TRPA1 mRNA expression and phosphorylated p38 (p-p38)/ MAPK expression. BAY 11-7085, pyrrolidine dithiocarbamate, SB202190, and 1400W were applied 30 minutes before LPS stimulation. JT010 (200 nmol/L) was applied for 180 minutes or 8 days to evaluate the effect on phosphorylated extracellular signal-regulated kinase (ERK)/MAPK expression and odontoblastic/osteoblastic marker mRNA 
expression, respectively. A-967079 $(2 \mu \mathrm{mol} / \mathrm{L})$ was applied 30 minutes before JT010 stimulation. Icilin was applied for 3 or 7 days to evaluate the effect of odontoblastic/osteoblastic marker mRNA expression and mineralization. HC030031 was applied 30 minutes before icilin stimulation.

\section{Measurement of Nitrogen Dioxide}

hDPCs were cultured in 96-well plates $\left(2 \times 10^{4}\right.$ cells/well). Phenol red-free $\alpha$-minimum essential medium (Wako) was used for cell culture. The nitrogen dioxide concentration in the medium was measured by Griess regents ( $1 \%$ sulfanilamide, $0.1 \%$ naphthylethylenediamine dihydrochloride, and $2.5 \%$ phosphoric acid). ${ }^{19}$ Absorbance was measured at 570 $\mathrm{nm}$ using an immunoplate reader (ImmunoMini NJ-2300; Narge Nunc/Thermo Fisher Scientific, Waltham, MA). Sodium nitride was used as an analytical reference standard.

\section{Western Blot Analysis}

hDPCs $\left(5 \times 10^{4}\right.$ cells/well $)$ were cultured in 24 -well plates with $\alpha$-minimum essential medium. After stimulation, the cells were lysed in radioimmunoprecipitation assay buffer $(50 \mathrm{mmol} / \mathrm{L}$ Tris-HCl, $\mathrm{pH} 8.0,150 \mathrm{mmol} / \mathrm{L}$ sodium chloride, $0.5 \mathrm{w} / \mathrm{v} \%$ sodium deoxycholate, $0.1 \mathrm{w} / \mathrm{v} \%$ SDS, and $1.0 \mathrm{w} / \mathrm{v} \% \mathrm{NP}-40$ substitute) containing a protease inhibitor cocktail (cOmplete; Roche/Sigma-Aldrich) and phosphatase inhibitor cocktail (PhosSTOP; Sigma-Aldrich). Then, $10 \mu \mathrm{L}$ of cell lysate $\left(5 \times 10^{4}\right.$ cells $/ 100 \mu \mathrm{L}$ radioimmunoprecipitation assay buffer) was applied to $10 \%$ SDS-PAGE. Separated proteins were electrophoretically transferred to a polyvinylidene difluoride membrane (Amersham Hybond P PVDF 0.45; GE Healthcare, Chicago, IL). After immersing and shaking in a nonprotein blocking reagent (EzBlock Chemi; ATTO, Tokyo, Japan), the membrane was incubated with the following primary antibodies: rabbit anti-TRPA1 (1:200; ab31486; Abcam), rabbit anti-HIF1 $\alpha$ (1:2000; GTX127309; GeneTex, Irvine, CA), mouse anti-p38/MAPK (1:5000; 612168; BD Biosciences, San Jose, CA), mouse anti-p-p38/MAPK (1:2500; 612280; BD Biosciences), mouse anti-ERK (1:4000; 610030; BD Biosciences), mouse anti-phosphorylated ERK (1:1000; 612358; BD Biosciences), mouse anti-nuclear factor erythroid-2-related factor 2 (NRF2; 1:500; sc-365949; Santa Cruz Biotechnology, Dallas, TX), and horseradish peroxidase-labeled anti-glyceraldehyde 3-phosphate dehydrogenase (1:4000; MBL, Nagoya, Japan). Horseradish peroxidase-conjugated goat anti-rabbit and goat anti-mouse IgGs (1:1000; Jackson, West Grove, PA) were used as secondary antibodies. A chemiluminescent horseradish peroxidase substrate (Immobilon; Millipore, Burlington, MA) was used for development. Images were captured by an LAS3000 mini-imaging system (Fujifilm, Tokyo, Japan). The pixel density was measured with ImageJ software version 1.53a (NIH, Bethesda, MD; https://imagej.nih.gov/ij). Bands were quantitated by densitometry, and their ratios were calculated. Each experiment was performed at least three times.

\section{Cell Proliferation Assay}

hDPCs $\left(3 \times 10^{3}\right.$ cells/well) were seeded in 96-well plates. After 24 hours of culture, the media were changed to the culture medium with or without TRPA1 agonist. Cell proliferation was measured with a WST-8 assay (CCK-8; Dojindo Molecular Technologies) at 48 and 72 hours.

\section{Quantitative RT-PCR}

Total RNA was extracted using QuickGene RNA cultured cell kit S (RC-S; Wako). The extracted total RNA (300 ng) was reverse transcribed to cDNA using PrimeScript RT Master Mix (Takara, Shiga, Japan). Quantitative RT-PCR was performed using specific primers (Table 1), CFX96 (Bio-Rad, Hercules, CA), and GoTaq qPCR Master Mix (Promega, Madison, WI). Relative gene expression values were calculated as $2_{\mathrm{T}}^{-\Delta \Delta \mathrm{C}} . \mathrm{C}_{\mathrm{T}}$ represents threshold cycle, and $\Delta \mathrm{C}_{\mathrm{T}}$ represents $\mathrm{C}_{\mathrm{T}}$ of target gene $-\mathrm{C}_{\mathrm{T}}$ of internal control gene ( $\beta$-actin or glyceraldehyde 3-phosphate dehydrogenase). $\Delta \Delta \mathrm{C}_{\mathrm{T}}$ represents $\Delta \mathrm{C}_{\mathrm{T}}$ of experimental group $\Delta \mathrm{C}_{\mathrm{T}}$ of control. Parallel reactions were run for each RNA sample in the absence of reverse transcriptase to confirm the absence of genomic contamination.

\section{Mineralized Nodule Formation Assay}

For the mineralized nodule formation assay, cloned mouse dental papilla (MDP) cells established from incisor apical buds of Institute of Cancer Research mice, which possessed the potential for odontogenic/osteogenic differentiation, were used. ${ }^{20,21}$

MDP cells $\left(1 \times 10^{4}\right.$ cells/well; 48-well plate $)$ were cultured in osteogenic medium containing L-ascorbic acid magnesium salt $(0.2 \mathrm{mmol} / \mathrm{L} ; 013-12061 ;$ Wako $)$ and $\beta$-glycerophosphate $(3.0 \mathrm{mmol} / \mathrm{L} ; \mathrm{G} 9422$; Sigma-Aldrich) for 7 days. Mineralized nodules were stained with alizarin red S (011-01192; Wako). The mineralized nodule density was measured by ImageJ software.

\section{Transfection}

hDPCs $\left(1 \times 10^{5}\right.$ cells/well $)$ were seeded in 12 -well plates. The cells were transfected with an NRF2 overexpression vector (pcDNA3-EGFP-C4-NRF2) and HIF1 $\alpha$ overexpression vector (HA-HIF1 $\alpha$-pcDNA3) using TransIT2020 (Mirus, Madison, WI) for 24 hours. pcDNA3-EGFPC4-Nrf2 (Addgene, Watertown, MA; 215493) was a gift from Yue Xiong (University of North Carolina, Chapel Hill, NC), ${ }^{22}$ and HA-HIF1a-pcDNA3 (Addgene; 18949) was a gift from William Kaelin (Harvard Medical School, Boston, MA). ${ }^{23}$ pcDNA EGFP (EGFP cDNA inserted into 
Table 1 Primer Sequences Used for Quantitative RT-PCR

\begin{tabular}{|c|c|c|c|c|}
\hline Species & Gene & Primer sequence & Accession no. & Size, bp \\
\hline \multirow[t]{10}{*}{ Human } & \multirow[t]{2}{*}{ TRPA1 } & Forward: 5'-СTTGTTTCCTTCACAАTATTTGTC-3' & \multirow[t]{2}{*}{ NM_007332 } & \multirow[t]{2}{*}{142} \\
\hline & & Reverse: 5'-TCTCTAAGCTGGTATGAAGTTCCAC-3' & & \\
\hline & NFE2L2 & Reverse: 5'-TCTGAGCAGCCACTTTATTCTTACC-3' & NM_001313904 & 122 \\
\hline & \multirow[t]{2}{*}{ HMOX1 } & Forward: 5'-AGAGAATGCTGAGTTCATGAGGA-3' & \multirow[t]{2}{*}{ NM_002133 } & \multirow[t]{2}{*}{166} \\
\hline & & Reverse: 5'-CAGCTCTTCTGGGAAGTAGACAG-3' & & \\
\hline & \multirow[t]{2}{*}{$A L P L$} & Forward: 5'-ATGCTGAGTGACACAGACAAGAAG-3' & \multirow[t]{2}{*}{ NM_000478 } & \multirow[t]{2}{*}{124} \\
\hline & & Reverse: 5'-GGTAGTTGTTGTGAGCATAGTCCAC-3' & & \\
\hline & \multirow[t]{2}{*}{ NOS2 } & Forward: 5'-CTCAGAGTACAGCAAGTGGAAGTT-3' & \multirow[t]{2}{*}{ NM_000625 } & \multirow[t]{2}{*}{132} \\
\hline & & Reverse: 5'-GAGTAGAACCTGGGCTTCAGAAT-3' & & \\
\hline & ACTB & Forward: 5'-CTGACTGACTACCTCATGAAGATCC-3' & NM_001101 & 102 \\
\hline & $A c t b$ & Reverse: 5'-AATGATCTTGATCTTCATGGTGCTA-3' & NM_007393 & 122 \\
\hline
\end{tabular}

Accession numbers available at $h$ ttps://www.ncbi.nlm.nih.gov/nuccore.

pcDNA3.1) was used as a mock vector. Transfection efficiency was evaluated using HEK293T cells.

\section{Immunocytochemistry}

hDPCs were seeded in glass bottom dishes $\left(2 \times 10^{5}\right.$ cells/ well) and cultured for immunofluorescence staining. After fixation with $4 \%$ paraformaldehyde $\left(4{ }^{\circ} \mathrm{C} ; 10\right.$ minutes $)$, the cells were incubated with a mouse anti-NRF2 antibody (1:500; sc-365949; Santa Cruz Biotechnology) at $4^{\circ} \mathrm{C}$ overnight, followed by a donkey anti-mouse Ig conjugated with Alexa Fluor 568 (1:500; ab175700; Abcam) at room temperature for 60 minutes. DAPI was used for counterstaining. NRF2 protein localization in hDPCs was evaluated under a confocal microscope (SP8; Leica Microsystems, Wetzlar, Germany).

\section{$\mathrm{Ca}^{2+}$ Imaging}

Intracellular calcium $\left(\mathrm{Ca}^{2+}\right)$ was estimated using Calcium kit-Fluo4 (CS22; Dojindo Molecular Technologies), according to the manufacturer's instructions. hDPCs were seeded into a 96-well plate $\left(2 \times 10^{4}\right.$ cells/well $)$ and cultured overnight. The culture medium was then replaced with loading buffer $(100 \mu \mathrm{L} /$ well $)$. After 1 hour of incubation, the cells were washed with prewarmed phosphate-buffered saline and then prewarmed recording medium $(100 \mu \mathrm{L} /$ well $)$ was added. Fluorescent signals (excitation wavelength, 485 $\mathrm{nm}$; emission wavelength, $535 \mathrm{~nm}$ ) were recorded every 5 seconds for 3 minutes with test regents under a fluorescence microscope (Axio Observer Z1; Zeiss, Jena, Germany). JT010 $(2 \mu \mathrm{mol} / \mathrm{L})$ and A-967079 $(2 \mu \mathrm{mol} / \mathrm{L})$ were used for a TRPA1 agonist and antagonist, respectively. A-967079 was applied 10 seconds after or 300 seconds before JT010 stimulation. Mean fluorescence intensity in each image was calculated using the ImageJ software; following subtraction of background fluorescence intensity, the mean fluorescence intensity in each image was normalized by the total cell area. Fluorescence intensity of the cells without JT010 stimulation was used as a background control.

\section{Statistical Analysis}

Kolmogorov-Smirnov test was performed to evaluate the normality of each group, then the $t$-test was used for comparison of two groups, and one-way analysis of variance and the Tukey-Kramer test were used for multiple comparisons. $\mathrm{R}$ software version 4.0.1 (R-Project, Vienna, Austria) was used for statistical analysis. $P<0.05$ was considered as significant.

\section{Results}

Deep Caries Increase the Number of TRPA1-Positive Odontoblasts

In intact teeth, odontoblasts expressing nestin were arranged regularly in the outermost layer of the pulp and extended long processes into the dentin (Figure 1, A and C). In teeth with deep caries, tertiary dentin was observed subjacent to the primary dentin (Figure 1F). The number of odontoblasts was decreased compared with intact teeth, and some odontoblastic processes were shortened (Figure 1H). TRPA1 expression was hardly observed in the dental pulp of intact teeth (Figure 1B), whereas TRPA1-positive cells were observed in the dental pulp of carious teeth (Figure 1G). In particular, TRPA1 was highly expressed in nestin $^{+}$odontoblasts located along the tertiary dentin-dental 


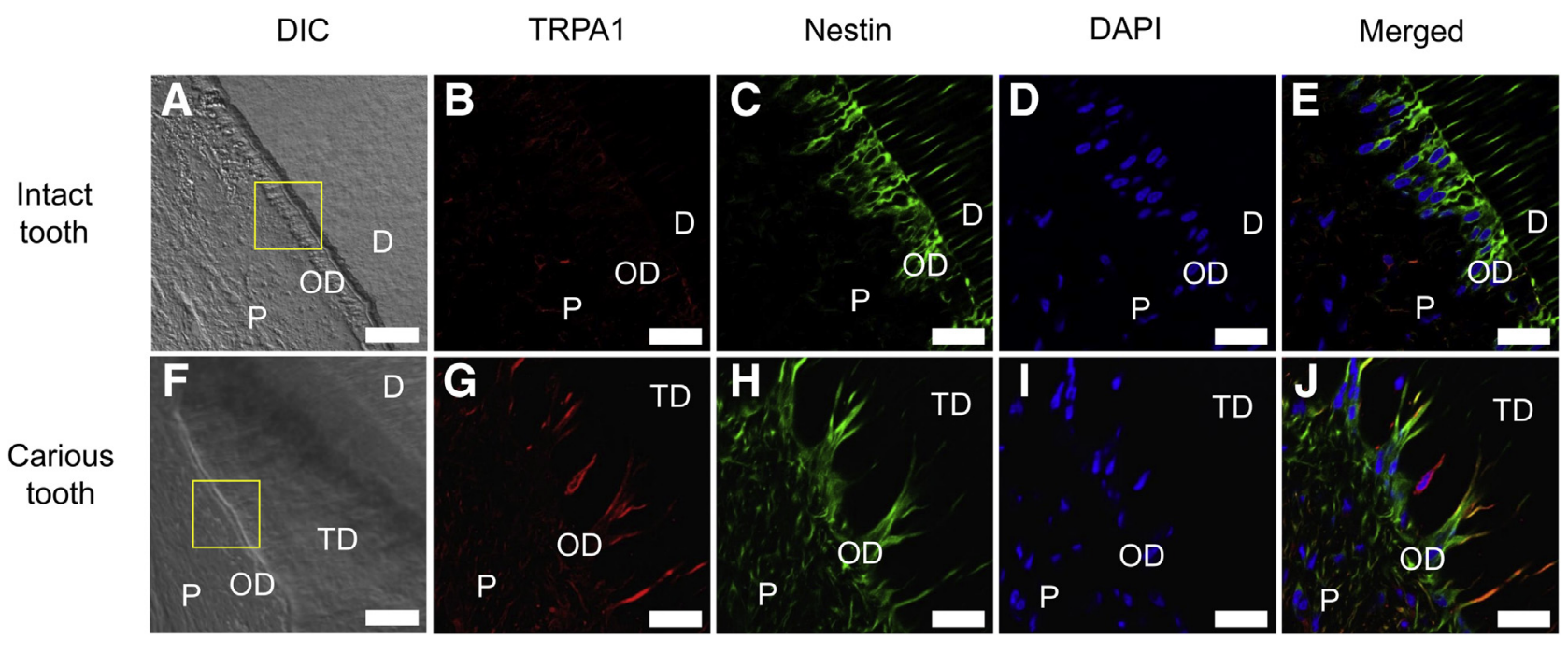

Figure 1 Immunofluorescence staining of TRPA1 and nestin in human intact teeth $(\mathbf{A}-\mathbf{E})$ and human teeth with deep caries (F-J). A and $\mathbf{F}$ : Phasecontrast images. $\mathbf{B}-\mathbf{E}$ and $\mathbf{G}-\mathbf{J}$ : High-magnification images of the boxed areas in $\mathbf{A}(\mathbf{B}-\mathbf{E})$ and $\mathbf{F}(\mathbf{G}-\mathbf{J})$, showing double immunofluorescence staining of TRPA1 (red) and nestin (green). Nuclei are labeled with DAPI (blue). $n=3$ for intact and carious teeth (A-J). Scale bars: $25 \mu \mathrm{m}(\mathbf{B}-\mathbf{E}$ and $\mathbf{G}-\mathbf{J}) ; 100 \mu \mathrm{m}(\mathbf{A}$ and F). D, dentin; DIC, differential interference contrast; OD, odontoblastic layer; P, pulp; TD, tertiary dentin.

pulp interface (Figure 1J), compared with intact tooth odontoblasts (Figure 1E). Nuclei are labeled with DAPI (Figure 1, D and I).

\section{LPS Stimulation Induces TRPA1 Expression via the N0 Signaling Cascade}

Expression of TRPA1 mRNA was up-regulated in LPSstimulated hDPCs at 24 and 48 hours, and its protein expression was increased at 48 hours after LPS stimulation $(P<0.05)$ (Figure 2A). Involvement of the NF- $\mathrm{BB}$, which is a major component of toll-like receptor $2 / 4$ signaling pathway activated by LPS, was evaluated at first. However, expression of TRPA 1 mRNA in LPS-stimulated hDPCs was independent of NF- $\kappa \mathrm{B}$ signaling inhibitors BAY 11-7085 $(1 \mu \mathrm{mol} / \mathrm{L})$ and pyrrolidine dithiocarbamate $(10 \mu \mathrm{mol} / \mathrm{L})$ (Supplemental Figure S1). Next, NO, which plays a key role in the pathogenesis of inflammation, ${ }^{24}$ was evaluated. Expression of NOS2 mRNA and NO synthesis were upregulated in LPS-stimulated hDPCs, and significant increases were observed at 24 and 48 hours after LPS stimulation $(P<0.05)$ (Figure $2 \mathrm{~B})$. Then, NOR5, a typical NO donor, and $1400 \mathrm{~W}$, a typical iNOS inhibitor, were applied to hDPCs. Expression of TRPA1 mRNA in hDPCs was increased and decreased significantly in the presence of NOR5 and $1400 \mathrm{~W}$, respectively $(P<0.05)$ (Figure $2 \mathrm{C}$ ).

\section{MAPK Signaling Is Involved in TRPA1 Expression Downstream of NO Signaling}

NO signaling promotes activation of the transcription factor NRF2. ${ }^{25}$ Translocation of NRF2 from the cytoplasm to nucleus was observed in NOR5-applied hDPCs (Supplemental Figure S2A), and mRNA expression of
NRF2 (official name NFE2L2) and heme oxygenase-1 (HO1; official name $H M O X 1$ ), a target of NRF2, was increased significantly in NOR5-applied hDPCs (Supplemental Figure S2B). However, enforced expression of NRF2 did not increase TRPA1 mRNA expression in hDPCs, whereas mRNA expression of $\mathrm{HO}-\mathrm{l}$ was increased in NRF2transfected hDPCs (Supplemental Figure S3A). Enforced expression of NRF2 protein was confirmed in HEK293T cells (Supplemental Figure S3B).

The p38/MAPK signaling pathway is also a target of NO signaling. ${ }^{26}$ Therefore, expression of p-p38/MAPK was evaluated in NOR5-applied hDPCs. Up-regulation of p-p38/ MAPK was induced in NOR5-applied hDPCs at 0.5 and 1 hour (Figure 2D). In addition, expression of TRPA1 mRNA in LPS-stimulated hDPCs was down-regulated significantly by application of SB202190, a typical p38/MAPK inhibitor (Figure 2E). Up-regulation of p-p38/MAPK expression was also detected in LPS-stimulated hDPCs at 0.5 and 1 hour (Supplemental Figure S4). Moreover, the involvement of HIF1 $\alpha$, which is also a target of LPS signaling, ${ }^{27}$ was evaluated in the expression of TRPA1. However, enforced expression of HIF1 $\alpha$ significantly down-regulated the expression of TRPA1 mRNA (Supplemental Figure S5A). Enforced expression of HIF1 $\alpha$ protein was confirmed in hDPCs (Supplemental Figure S5B).

\section{TRPA1 Activation Promotes Differentiation and Mineralization of Dental Pulp Cells}

The function of TRPA1 was evaluated in hDPCs. Activation of TRPA1 channels by JT010, a selective TRPA1 agonist, induced an increase of intracellular $\mathrm{Ca}^{2+}$, which was inhibited immediately by A-967079, a selective TRPA1 inhibitor in hDPCs (Figure 3A). Furthermore, A-967079 

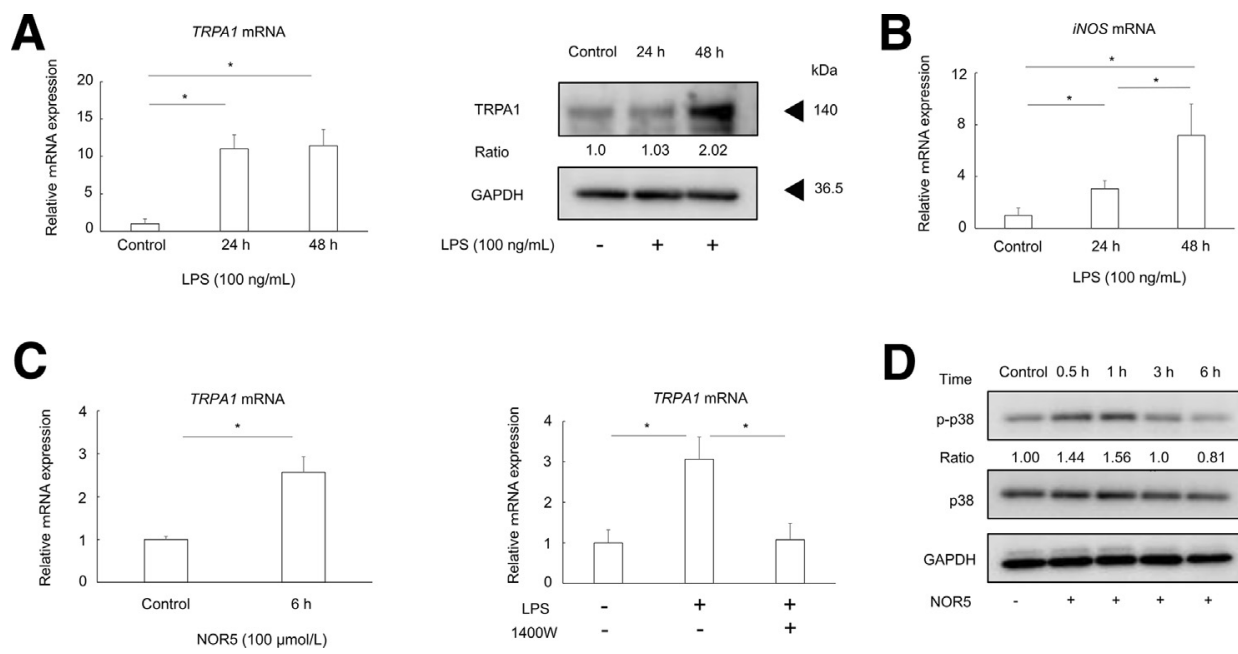

Figure 2 Effect of nitric oxide (NO) signals on up-regulation of TRPA1 expression in lipopolysaccharide (LPS)-stimulated human dental pulp cells. A: Expression of TRPA $1 \mathrm{mRNA}$ and protein is increased significantly at 24 and 48 hours after LPS $(100 \mathrm{ng} / \mathrm{mL})$ stimulation. B: NOS2 mRNA expression and the N0 ${ }_{2}^{-}$ concentration are increased by LPS stimulation in a time-dependent manner. C: Expression of TRPA1 is up-regulated significantly by NOR5 (100 $\mu$ mol/L). The 1400W $(1 \mu \mathrm{mol} / \mathrm{L})$ treatment attenuates LPS-induced TRPA1 expression at 48 hours. D: Up-regulation of phosphorylated p38 protein is detected at 0.5 and 1 hour after NOR5 treatment. E: Expression of LPS-induced TRPA1 mRNA is inhibited in the presence of SB202190 (1 $\mu \mathrm{mol} / \mathrm{L})$ at $48 \mathrm{hours}$. Western blotting was performed in triplicate, and typical results are shown. Data are expressed as means $\pm \mathrm{SD}(\mathbf{A}-\mathbf{C}$ and $\mathbf{E}) . n=4(\mathbf{B}-\mathbf{E})$. ${ }^{\star} P<0.05$. GAPDH, glyceraldehyde $3-$ phosphate dehydrogenase.

pretreatment also blocked JT010-induced $\mathrm{Ca}^{2+}$ influx effectively (Figure 3, B and C). Next, the effect of TRPA1 activation on odontoblastic/osteoblastic marker expression was evaluated. JT010 induced up-regulation of collagen type I $\propto 1$ chain (COL1A1) and alkaline phosphatase (ALPL) mRNA expression in hDPCs $(P<0.05)$ (Figure 4A), which was blocked by A-967079 $(P<0.05)$ (Figure 4A). Activation of TRPA1 was independent of cell proliferation (Supplemental Figure S6). Moreover, icilin, an agonist of TRPA1, induced up-regulation of secreted phosphoprotein 1 (Spp1) mRNA expression at 72 hours (Figure 4B) and enhanced mineralized nodule formation at 7 days in MDPs (Figure 4C). The icilin-induced mineralized nodule formation in MDPs was inhibited by application of HC-030031, a TRPA1 antagonist, at 7 days (Figure 4C). An increase of phosphorylated ERK1/2 expression was observed at 5 and 30 minutes in JT010-applied hDPCs (Figure 4D).

\section{Discussion}

TRPA1 was expressed in odontoblasts aligned along tertiary dentin formed under a carious lesion (Figure 1G), TRPA1 expression was increased in LPS-stimulated hDPCs (Figure 2A), and TRPA1 induced differentiation and promoted mineralization of dental pulp cells (Figure 4, A and B). These findings suggest that TRPA1 plays a role in the defense or repair processes of the dentin or pulp complex represented by tertiary dentinogenesis, where new mineralized tissue is formed by newly generated odontoblast cells originating from undifferentiated precursors in response to dentinal tubule-derived bacterial stimulation. ${ }^{28}$
LPS-induced signal transmission is activated through LPS binding to toll-like receptors, ${ }^{29}$ which triggers intracellular signaling cascades leading to the activation of transcription factors, such as NF- $\kappa \mathrm{B}^{30}$ and NRF2. ${ }^{31}$ Activation of NF- $\kappa \mathrm{B}$ signaling is observed in LPS-stimulated $\mathrm{hDPCs},{ }^{32,33}$ and NF- $\kappa \mathrm{B}$ signals activated by tumor necrosis factor- $\alpha$ or IL- $1 \alpha$ up-regulate HIF $1 \alpha$ that binds to a specific site on the TRPA1 gene and promotes TRPA1 expression in human synoviocytes. ${ }^{15}$ However, enforced expression of HIF1 $\alpha$ did not up-regulate TRPA1 mRNA expression, but HIF1 $\alpha$ suppressed TRPAl expression in hDPCs (Supplemental Figure S5A), suggesting that mechanisms that induce TRPAl expression differ in different cells/tissues.

NO signaling is also a signaling cascade of LPS-activated toll-like receptor $2 / 4^{34}$ and NOR5, a typical NO donor, promoted TRPA1 expression (Figure 2C). Most NO synthesis in response to LPS depends on iNOS. ${ }^{35}$ Generally, NF- $\mathrm{BB}$ signaling induces expression of iNOS, ${ }^{36}$ but other pathways, such as interferon- $\beta-$ and/or $\quad c-f o s / c-$ Jun-dependent signaling, are also involved in iNOS expression. $^{37,38}$ In this study, NF- $\kappa \mathrm{B}$ inhibitors did not interfere with up-regulated TRPA1 expression in LPSstimulated hDPCs (Supplemental Figure S1). Collectively, results in this study suggest that NF- $\kappa \mathrm{B}-$ independent $\mathrm{NO}$ signaling pathways are predominantly involved in the induction of TRPA1 expression in hDPCs.

NO stimulates NRF2 signaling, ${ }^{25}$ and TRPA1 expression is induced by NRF2 in cancer cells. ${ }^{39}$ In this study, mRNA expression of NRF2 was up-regulated in NO donor-applied hDPCs (Supplemental Figure S2B), but enforced expression of NRF2 did not induce TRPA1 mRNA expression. mRNA expression of $\mathrm{HO}-1$ downstream of the NRF2 signaling 
A

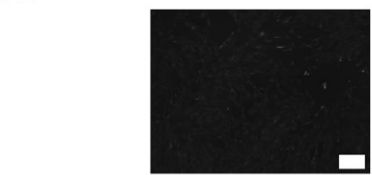

Mean fluorescence $\quad 4.3$ intensity

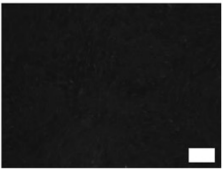

Mean fluorescence $\quad 4.5$ intensity
$10 \mathrm{~s}$

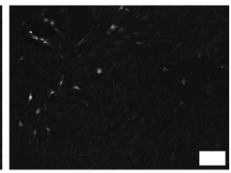

5.2

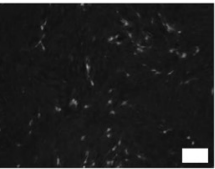

7.5
$25 s$

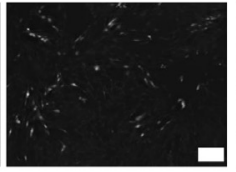

7.4

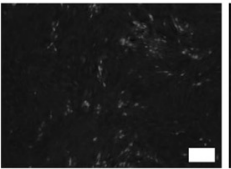

7.1
$50 \mathrm{~s}$

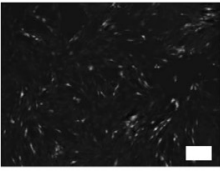

9.6

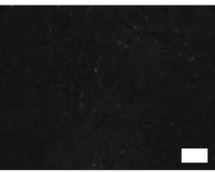

5.3
$75 \mathrm{~s}$

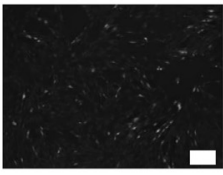

8.1

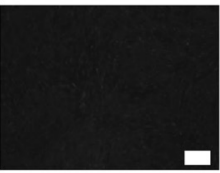

5.1
$100 \mathrm{~s}$

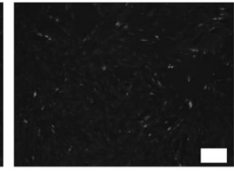

7.2

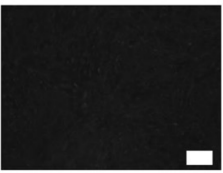

5.2

$\triangle:$ JT010 (2 $\mu \mathrm{mol} / \mathrm{L})$ application

A : A-967079 (2 $\mu \mathrm{mol} / \mathrm{L})$ application

B

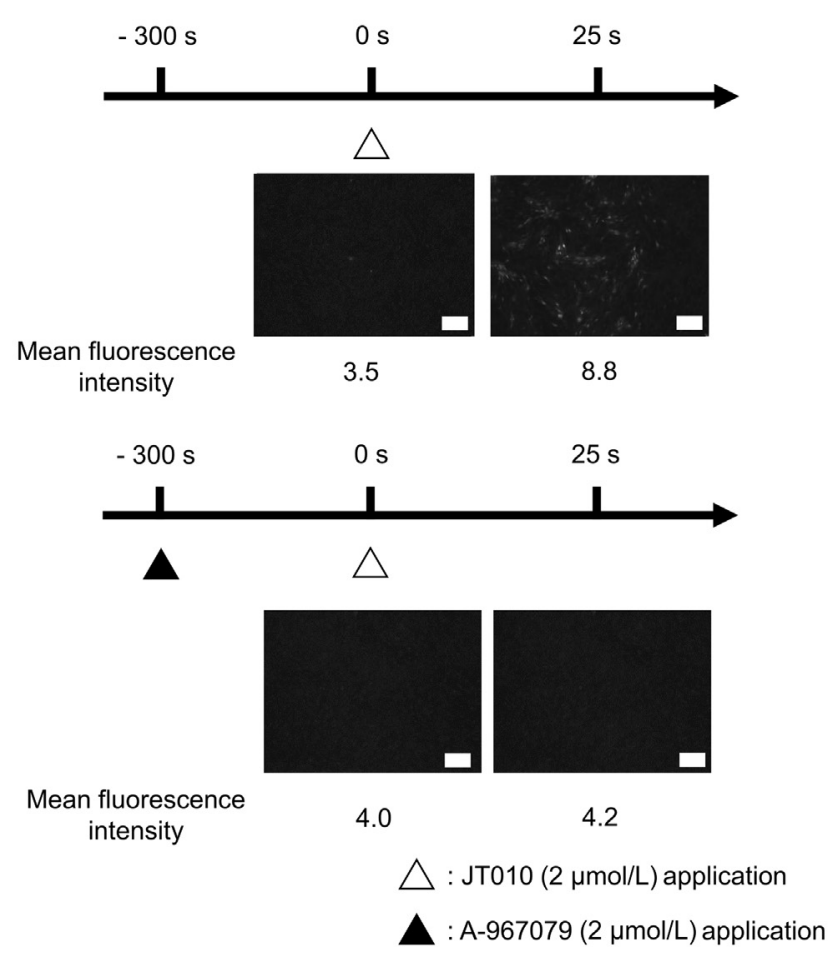

C

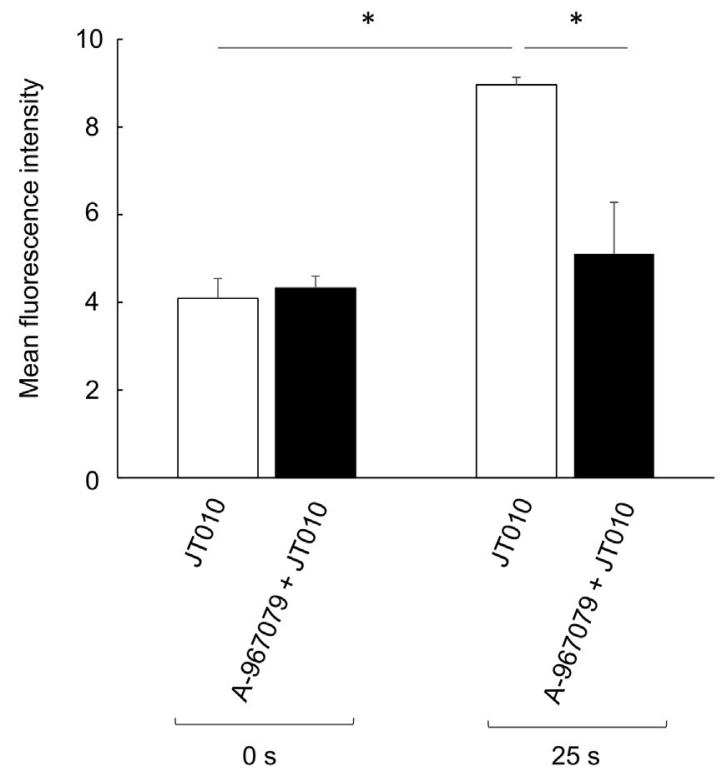

Figure 3 Detection of calcium $\left(\mathrm{Ca}^{2+}\right)$ influx by $\mathrm{Ca}^{2+}$ imaging after activation of TRPA1 in human dental pulp cells (hDPCs). A: A-967079 (selective TRPA1 inhibitor; $2 \mu \mathrm{mol} / \mathrm{L}$ ) was applied 10 seconds after JT010 (selective TRPA1 activator; $2 \mu \mathrm{mol} / \mathrm{L}$ ) treatment. Fluorescence intensity per cell area in each image was quantified by ImageJ software version 1.53a. Top row: JT010 application increases intracellular $\mathrm{Ca}^{2+}$. Bottom row: A-967079 blocks the intracellular Ca ${ }^{2+}$ increase induced by JT010 (2 $\mu \mathrm{mol} / \mathrm{L})$. B: JT010 was applied to A-967079 pretreated hDPCs. Typical results are shown. Top row: Intracellular Ca ${ }^{2+}$ is increased by JT010 application at 25 seconds. Bottom row: A-967079 pretreatment blocks the $\mathrm{Ca}^{2+}$ influx effectively induced by JT010 ( $\left.2 \mu \mathrm{mol} / \mathrm{L}\right)$. C: The quantitative analysis of figure B. Data are expressed as means \pm SD (C). $n=3(\mathbf{A}-\mathbf{C}) .{ }^{*} P<0.05$. Scale bar $=200 \mu \mathrm{m}(\mathbf{A}$ and $\mathbf{B})$.

pathway $^{25}$ was up-regulated (Supplemental Figure S3A). Taken together, NRF2 signaling is independent to induction of TRPA1 mRNA expression in hDPCs.

p38/MAPKs are activated by a wide range of cellular stresses and in response to inflammatory cytokines. ${ }^{40}$
Activation of the p38/MAPK cascade was induced by NO in hDPCs (Figure 2D), as reported previously. ${ }^{26} \mathrm{~A}$ p38 inhibitor blocked TRPA1 mRNA expression in LPSstimulated hDPCs (Figure 2E). These results suggest that p38/MAPK signaling, activated by NO, may be involved in 

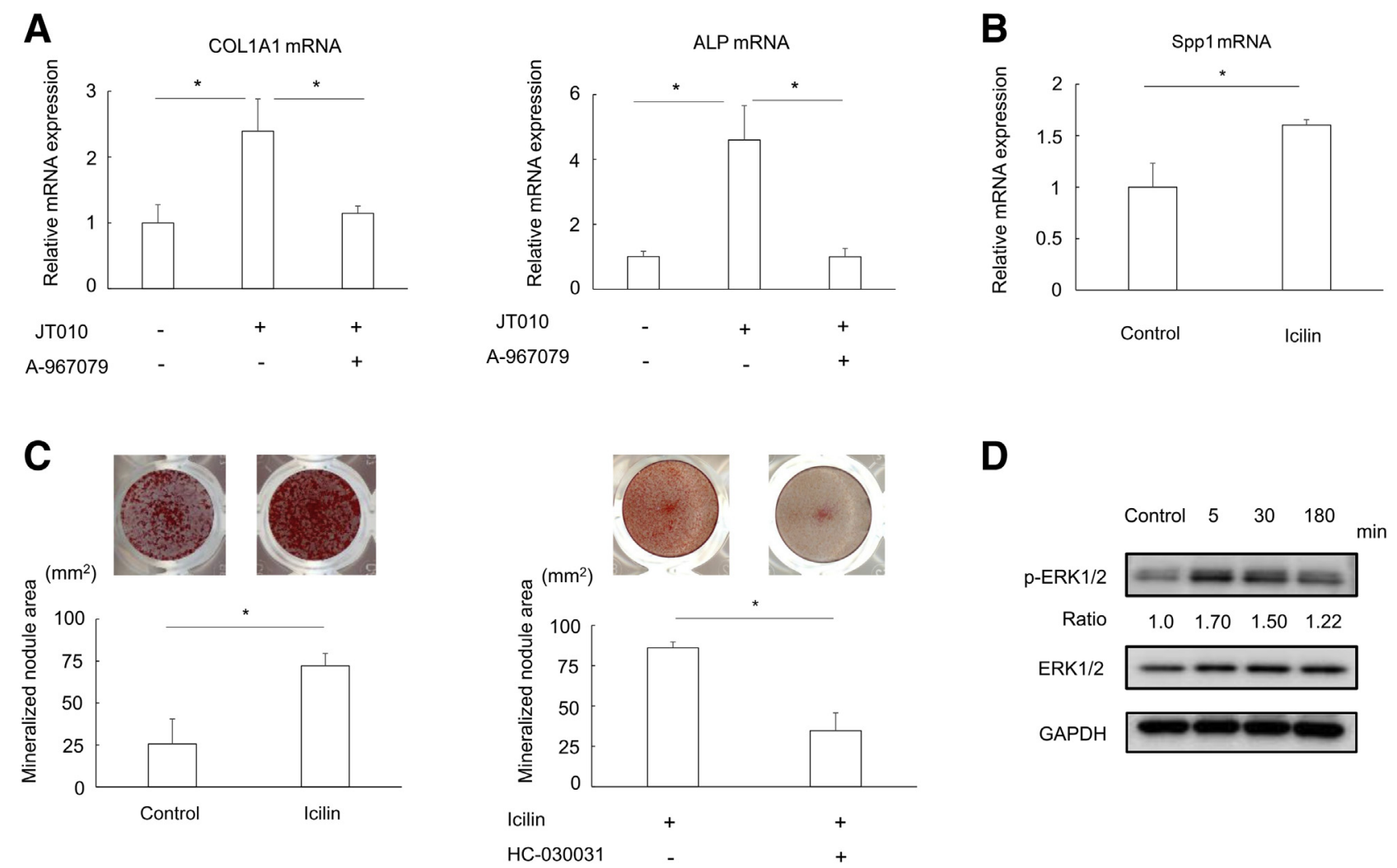

Figure 4 Effects of TRPA1 activation on odontoblastic differentiation and mineralization. A: Expression of collagen type I $\alpha 1$ chain (COL1A1) and alkaline phosphatase (ALPL) mRNA is increased in human dental pulp cells by JT010 (TRPA1 activator; $200 \mathrm{nmol} / \mathrm{L}$ ) application at 8 days. The up-regulation is inhibited by pretreatment with A-967079 (TRPA1 inhibitor; $2 \mu \mathrm{mol} / \mathrm{L}$ ). B: Secreted phosphoprotein 1 (Spp1) mRNA is up-regulated in mouse dental papilla cells (MDPs) by $2 \mu \mathrm{mol} / \mathrm{L}$ icilin treatment at 3 days. C: Icilin treatment $(2 \mu \mathrm{mol} / \mathrm{L})$ promotes nodule formation in MDPs at 7 days, which is significantly inhibited by HC$030031(10 \mu \mathrm{mol} / \mathrm{L})$ application. HC-030031 was applied 30 minutes before icilin treatment. D: Phosphorylated extracellular signal-regulated kinase 1/2 ( $\mathrm{p}$ ERK1/2) protein expression is increased by JT010 $(200 \mathrm{nmol} / \mathrm{L})$ application. Western blotting was performed in triplicate, and typical results are shown. Data are expressed as means $\pm \mathrm{SD}(\mathbf{A}-\mathbf{C}) . n=4(\mathbf{A}-\mathbf{D}) .{ }^{*} P<0.05 . \mathrm{GAPDH}$, glyceraldehyde 3-phosphate dehydrogenase.

the induction of TRPA1 expression in LPS-stimulated hDPCs. p38/MAPK-mediated TRPA1 up-regulation has been reported to be induced by long-term tumor necrosis factor- $\alpha$ stimulation in odontoblast-like cells. ${ }^{17}$ Moreover, phosphorylation of p38/MAPK was induced by LPS stimulation at 0.5 to 1 hour (Supplemental Figure S4), which may be mediated by NF- $\kappa \mathrm{B}$ signaling. ${ }^{41}$ However, NF$\kappa \mathrm{B}-$ specific inhibitors BAY11-7085 and pyrrolidine dithiocarbamate did not down-regulate TRPA1 mRNA expression (Supplemental Figure S1), suggesting that p38 signaling in response to TRPA1 expression may be mediated by NO signaling.

Activation of TRPA1 promotes a wide range of physiological events in various cell types. ${ }^{42}$ Insulin release in rat pancreatic $\beta$ cell lines, ${ }^{9}$ adrenomedullin synthesis in rat small intestines, ${ }^{43}$ and proliferation of stem cells in drosophila midgut ${ }^{44}$ are accelerated by TRPA1 activation. The major intracellular process induced by activated TRPA1 is $\mathrm{Ca}^{2+}$ influx ${ }^{6}$ that was detected in JT010stimulated hDPCs (Figure 3). Following the $\mathrm{Ca}^{2+}$ influx, nuclear factor of activated $\mathrm{T}$ cells and Ras-ERK/MAPK are induced by TRPA1 activation. ${ }^{44-46}$ Nuclear factor of activated $\mathrm{T}$ cells is involved in the development and function of regulatory $\mathrm{T}$ cells and osteoclast differentiation, and regulates cell cycle-, apoptosis-, angiogenesis-, and metastasis-related genes. ${ }^{47-49}$

In this study, phosphorylation of ERK1/2 was promoted in JT010-applied hDPCs (Figure 4D). ERK1/2 are members of the MAPK family, and the ERK1/2 phosphorylation cascade plays an important role in physiological functions, such as cell proliferation and differentiation. ${ }^{50}$ ERK1/2 signaling regulates both in vitro osteoblast differentiation and in vivo bone formation. ${ }^{51}$ ERK1/2 signaling also promotes hDPC differentiation into odontoblasts. ${ }^{52}$

This study revealed that TRPA1-dependent $\mathrm{Ca}^{2+}$ influx caused activation of ERK $1 / 2$ signaling and subsequently induced up-regulation of $A L P L$ in hDPCs (Figure 4A). Furthermore, TRPA1 activation by the application of icilin increased Spp1 mRNA expression and promoted nodule formation in MDPs (Figure 4, B and C). These findings suggest that the activated TRPA1 potentially induces odontoblastic/osteoblastic differentiation via ERK1/2 signaling. Icilin is reported to activate not only TRPA1 but TRPM8, ${ }^{5}$ and thus involvement of TRPM8-derived signaling in odontoblastic/osteoblastic differentiation 
cannot be ruled out. Expression of TRPM8 in freshly isolated human odontoblasts has been previously reported. ${ }^{53}$ However, mineralized nodule formation induced by icilin was partially blocked by HC-030031, a selective TRPA1 antagonist (Figure 4C), indicating that TRPA1-derived signaling is involved, at least in part, in the mineralization in MDPs. In vivo immunohistochemistry revealed that TRPA1 was expressed in odontoblasts, which may actively form tertiary dentin in carious human tooth pulp (Figure 1J). It is tempting to speculate that such an action of TRPA1 contributes to tertiary dentin formation induced in response to transdentinal bacterial challenge and regarded as a defense mechanism equipped in the dentin-pulp complex, to protect it from microbial invasion.

In conclusion, TRPA1 expression was induced via NO/ p38 MAPK signaling in LPS-stimulated hDPCs, and TRPA1 agonists induced odontoblastic/osteoblastic differentiation and mineralization via $\mathrm{Ca}^{2+}$ influx followed by activation of ERK1/2 signaling.

\section{Acknowledgment}

We thank Mitchell Arico (Edanz Group, Fukuoka, Japan) for editing a draft of this article.

\section{Author Contributions}

K.T. and N.K. designed the study; K.T. performed experiments; M.K., S.N., M.F., K.N., and K.H. provided reagents and experimental materials; K.T. and N.K. analyzed the data; K.T., N.K., and T.O. wrote the manuscript.

\section{Supplemental Data}

Supplemental material for this article can be found at http://doi.org/10.1016/j.ajpath.2020.08.016.

\section{References}

1. Okiji T: Pulp as a connective tissue. Edited by Hargreaves KM, Goodis HE. In Seltzer and Bender's Dental Pulp. ed 2. Chicago, IL: Quintessence, 2012. pp. 67-89

2. Love RM, Jenkinson HF: Invasion of dentinal tubules by oral bacteria. Crit Rev Oral Biol Med 2002, 13:171-183

3. Dummer PM, Hicks R, Huws D: Clinical signs and symptoms in pulp disease. Int Endod J 1980, 13:27-35

4. Knowles CH, Aziz Q: Visceral hypersensitivity in non-erosive reflux disease. Gut 2008, 57:674-683

5. Story GM, Peier AM, Reeve AJ, Eid SR, Mosbacher J, Hricik TR, Earley TJ, Hergarden AC, Andersson DA, Hwang SW, McIntyre P, Jegla T, Bevan S, Patapoutian A: ANKTM1, a TRP-like channel expressed in nociceptive neurons, is activated by cold temperatures. Cell 2003, 112:819-829

6. Nilius B, Appendino G, Owsianik G: The transient receptor potential channel TRPA1: from gene to pathophysiology. Pflugers Arch 2012, 464:425-458

7. Nassini R, Pedretti P, Moretto N, Fusi C, Carnini C, Facchinetti F, Viscomi AR, Pisano AR, Stokesberry S, Brunmark C, Svitacheva N,
McGarvey L, Patacchini R, Damholt AB, Geppetti P, Materazzi S Transient receptor potential ankyrin 1 channel localized to nonneuronal airway cells promotes non-neurogenic inflammation. PLoS One 2012, 7:e42454

8. Earley S, Gonzales AL, Crnich R: Endothelium-dependent cerebral artery dilation mediated by TRPA 1 and $\mathrm{Ca}^{2+}$-activated $\mathrm{K}^{+}$channels. Circ Res 2009, 104:987-994

9. Cao DS, Zhong L, Hsieh TH, Abooj M, Bishnoi M, Hughes L, Premkumar LS: Expression of transient receptor potential ankyrin 1 (TRPA1) and its role in insulin release from rat pancreatic beta cells PLoS One 2012, 7:e38005

10. Jain A, Bronneke S, Kolbe L, Stab F, Wenck H, Neufang G: TRPchannel-specific cutaneous eicosanoid release patterns. Pain 2011, $152: 2765-2772$

11. El Karim IA, Linden GJ, Curtis TM, About I, McGahon MK, Irwin CR, Killough SA, Lundy FT: Human dental pulp fibroblasts express the "cold-sensing" transient receptor potential channels TRPA1 and TRPM8. J Endod 2011, 37:473-478

12. Obata K, Katsura H, Mizushima T, Yamanaka H, Kobayashi K, Dai Y, Fukuoka T, Tokunaga A, Tominaga M, Noguchi K: TRPA1 induced in sensory neurons contributes to cold hyperalgesia after inflammation and nerve injury. J Clin Invest 2005, 115:2393-2401

13. Antoniazzi C, Nassini R, Rigo FK, Milioli AM, Bellinaso F, Camponogara C, Silva CR, de Almeida AS, Rossato MF, De Logu F, Oliveira SM, Cunha TM, Geppetti P, Ferreira J, Trevisan G: Transient receptor potential ankyrin 1 (TRPA1) plays a critical role in a mouse model of cancer pain. Int J Cancer 2019, 144:355-365

14. Bátai IZ, Sár CP, Horváth Á, Borbély É, Bölcskei K, Kemény Á, Sándor Z, Nemes B, Helyes Z, Perkecz A, Mócsai A, Pozsgai G, Pintér E: TRPA1 ion channel determines beneficial and detrimental effects of GYY4137 in murine serum-transfer arthritis. Front Pharmacol 2019, 10:964

15. Hatano N, Itoh Y, Suzuki H, Muraki Y, Hayashi H, Onozaki K, Wood IC, Beech DJ, Muraki K: Hypoxia-inducible factor- $1 \alpha$ $(\mathrm{HIF} 1 \alpha)$ switches on transient receptor potential ankyrin repeat 1 (TRPA1) gene expression via a hypoxia response element-like motif to modulate cytokine release. J Biol Chem 2012, 287 31962-31972

16. El Karim IA, McCrudden MT, McGahon MK, Curtis TM, Jeanneau C, Giraud T, Irwin CR, Linden GJ, Lundy FT: About I: Biodentine reduces tumor necrosis factor alpha-induced TRPA1 expression in odontoblastlike cells. J Endod 2016, 42: 589-595

17. El Karim I, McCrudden MT, Linden GJ, Abdullah H, Curtis TM, McGahon M, About I, Irwin C, Lundy FT: TNF- $\alpha$-induced p38MAPK activation regulates TRPA1 and TRPV4 activity in odontoblast-like cells. Am J Pathol 2015, 185:2994-3002

18. Noda S, Kawashima N, Yamamoto M, Hashimoto K, Nara K, Sekiya I, Okiji T: Effect of cell culture density on dental pulp-derived mesenchymal stem cells with reference to osteogenic differentiation. Sci Rep 2019, 9:5430

19. Moorcroft MJ, Davis J, Compton RG: Detection and determination of nitrate and nitrite: a review. Talanta 2001, 54:785-803

20. Tsubakimoto T, Kousaka K, Saito M, Teranaka T: Immortalization of dental papilla cells differentiating into odontoblast in vitro. J Conserv Dent 2007, 50:292-301

21. Bakhit A, Kawashima N, Hashimoto K, Noda S, Nara K, Kuramoto M, Tazawa K, Okiji T: Strontium ranelate promotes odonto-/osteogenic differentiation/mineralization of dental papillae cells in vitro and mineralized tissue formation of the dental pulp in vivo. Sci Rep 2018, 8:9224

22. Furukawa M, Xiong Y: BTB protein Keap1 targets antioxidant transcription factor Nrf2 for ubiquitination by the Cullin 3-Roc1 ligase. Mol Cell Biol 2005, 25:162-171

23. Kondo K, Klco J, Nakamura E, Lechpammer M, Kaelin WG: Inhibition of HIF is necessary for tumor suppression by the von HippelLindau protein. Cancer Cell 2002, 1:237-246 
24. Sharma JN, Al-Omran A, Parvathy SS: Role of nitric oxide in inflammatory diseases. Inflammopharmacol 2007, 15:252-259

25. Li CQ, Kim MY, Godoy LC, Thiantanawat A, Trudel LJ, Wogan GN: Nitric oxide activation of Keap1/Nrf2 signaling in human colon carcinoma cells. Proc Natl Acad Sci U S A 2009, 106: $14547-14551$

26. Browning DD, McShane MP, Marty C, Ye RD: Nitric oxide activation of p38 mitogen-activated protein kinase in $293 \mathrm{~T}$ fibroblasts requires cGMP-dependent protein kinase. J Biol Chem 2000, 275: $2811-2816$

27. Fujii M, Kawashima N, Tazawa K, Hashimoto K, Nara K, Noda S, Kuramoto M, Orikasa S, Nagai S, Okiji T: HIF1 $\alpha$ inhibits LPSmediated induction of IL- 6 synthesis via SOCS3-dependent CEBP $\beta$ suppression in human dental pulp cells. Biochem Biophys Res Commun 2020, 522:308-314

28. Kawashima N, Okiji T: Odontoblasts: specialized hard-tissue-forming cells in the dentin-pulp complex. Congenit Anom (Kyoto) 2016, 56 : 144-153

29. Park BS, Lee JO: Recognition of lipopolysaccharide pattern by TLR4 complexes. Exp Mol Med 2013, 45:e66

30. Kawai T, Akira S: Signaling to NF-kappaB by Toll-like receptors. Trends Mol Med 2007, 13:460-469

31. Zhao C, Gillette DD, Li X, Zhang Z, Wen H: Nuclear factor E2related factor-2 (Nrf2) is required for NLRP3 and AIM2 inflammasome activation. J Biol Chem 2014, 289:17020-17029

32. Fujii M, Kawashima N, Tazawa K, Hashimoto K, Nara K, Noda S, Nagai S, Okiji T: Hypoxia-inducible factor $1 \alpha$ promotes interleukin $1 \alpha$ and tumour necrosis factor $\alpha$ expression in lipopolysaccharidestimulated human dental pulp cells. Int Endod J 2020, 53:636-646

33. Nara K, Kawashima N, Noda S, Fujii M, Hashimoto K, Tazawa K, Okiji T: Anti-inflammatory roles of microRNA 21 in lipopolysaccharide-stimulated human dental pulp cells. J Cell Physiol 2019, 234:21331-21341

34. Gatto M, de Abreu MM, Tasca KI, de Assis Golim M, da Silva LD, Simão JC, Fortaleza CM, de Campos Soares ÂM, Calvi SA: The involvement of TLR2 and TLR4 in cytokine and nitric oxide production in visceral leishmaniasis patients before and after treatment with anti-leishmanial drugs. PLoS One 2015, 10:e0117977

35. Bredt DS, Snyder SH: Nitric oxide: a physiologic messenger molecule. Annu Rev Biochem 1994, 63:175-195

36. Aktan F: iNOS-mediated nitric oxide production and its regulation. Life Sci 2004, 75:639-653

37. Jung DY, Lee H, Jung BY, Ock J, Lee MS, Lee WH, Suk K: TLR4, but not TLR2, signals autoregulatory apoptosis of cultured microglia: a critical role of IFN-beta as a decision maker. J Immunol 2005, 174 : $6467-6476$

38. Chen CC, Lin MW, Liang CJ, Wang SH: The anti-inflammatory effects and mechanisms of eupafolin in lipopolysaccharide-induced inflammatory responses in RAW264.7 macrophages. PLoS One 2016, 11:e0158662

39. Takahashi N, Chen HY, Harris IS, Stover DG, Selfors LM, Bronson RT, Deraedt T, Cichowski K, Welm AL, Mori Y, Mills GB, Brugge JS: Cancer cells co-opt the neuronal redox-sensing channel TRPA1 to promote oxidative-stress tolerance. Cancer Cell 2018, 33:985-1003

40. Zarubin T, Han J: Activation and signaling of the p38 MAP kinase pathway. Cell Res 2005, 15:11-18

41. Saha RN, Jana M, Pahan K: MAPK p38 regulates transcriptional activity of NF-kappaB in primary human astrocytes via acetylation of p65. J Immunol 2007, 179:7101-7109

42. Albarrán L, Lopez JJ, Dionisio N, Smani T, Salido GM, Rosado JA: Transient receptor potential ankyrin-1 (TRPA1) modulates storeoperated $\mathrm{Ca}(2+)$ entry by regulation of STIM1-Orai1 association. Biochim Biophys Acta 2013, 1833:3025-3034

43. Kono T, Kaneko A, Omiya Y, Ohbuchi K, Ohno N, Yamamoto M: Epithelial transient receptor potential ankyrin 1 (TRPA1)-dependent adrenomedullin upregulates blood flow in rat small intestine. Am J Physiol Gastrointest Liver Physiol 2013, 304:G428-G436

44. Xu C, Luo J, He L, Montell C, Perrimon N: Oxidative stress induces stem cell proliferation via TRPA1/RyR-mediated $\mathrm{Ca}^{2+}$ signaling in the Drosophila midgut. eLife 2017, 6:e22441

45. Lee KI, Lee HT, Lin HC, Tsay HJ, Tsai FC, Shyue SK, Lee TS: Role of transient receptor potential ankyrin 1 channels in Alzheimer's disease. J Neuroinflammation 2016, 13:92

46. Donnerer J, Liebmann I: Phosphorylation of ERK1/2 in dorsal root ganglia following sequential mustard oil and thermal stimulation of the rat hind paw. Pharmacology 2012, 89:7-12

47. Oh-hora M, Rao A: The calcium/NFAT pathway: role in development and function of regulatory T cells. Microbes Infect 2009, 11:612-619

48. Hogan PG, Chen L, Nardone J, Rao A: Transcriptional regulation by calcium, calcineurin, and NFAT. Genes Dev 2003, 17:2205-2232

49. Mognol GP, Carneiro FR, Robbs BK, Faget DV, Viola JP: Cell cycle and apoptosis regulation by NFAT transcription factors: new roles for an old player. Cell Death Dis 2016, 7:e2199

50. Buscà R, Pouysségur J, Lenormand P: ERK1 and ERK2 Map kinases: specific roles or functional redundancy? Front Cell Dev Biol 2016, 4:53

51. Matsushita T, Chan YY, Kawanami A, Balmes G, Landreth GE, Murakami S: Extracellular signal-regulated kinase 1 (ERK1) and ERK2 play essential roles in osteoblast differentiation and in supporting osteoclastogenesis. Mol Cell Biol 2009, 29:5843-5857

52. Mizumachi H, Yoshida S, Tomokiyo A, Hasegawa D, Hamano S, Yuda A, Sugii H, Serita S, Mitarai H, Koori K, Wada N, Maeda H: Calcium-sensing receptor-ERK signaling promotes odontoblastic differentiation of human dental pulp cells. Bone 2017, 101:191-201

53. Tazawa K, Ikeda H, Kawashima N, Okiji T: Transient receptor potential melastatin (TRPM) 8 is expressed in freshly isolated native human odontoblasts. Arch Oral Biol 2017, 75:55-61 